\title{
O USO DE BENS MÓVEIS COMO FORMA DE EXTINÇÃO DO CRÉDITO TRIBUTÁRIO POR MEIO DO INSTITUTO DA DAÇÃO EM PAGAMENTO
}

\section{THE USE OF MOVABLE PROPERTY AS A FORM OF EXTINCTION OF THE TAX CREDIT BY THE INSTITUTE OF DAMAGE IN PAYMENT}

\author{
JEAN CARLOS MOURA MOTA ${ }^{1}$ \\ LUÍS CARLOS ALCÂNTARA²
}

\begin{abstract}
Resumo: Este artigo prima pela revisão bibliográfica na forma narrativa, com uso do método dedutivo. Teve por objetivo compreender o instituto da dação em pagamento como forma de extinção do crédito tributário, sobretudo no que diz respeito ao uso de bens móveis por esse instituto. Essa temática vem sendo discutida a alguns anos, porém, ela ainda é causa de debates jurídicos, tendo sido editadas leis recentes sobre o tema, o que demonstra que persiste certa confusão, e arriscando brevemente um comentário, referido problema tem se dado por conta dos entendimentos conflitantes entre os próprios entes políticos. Assim, preliminarmente buscou-se apresentar os conceitos do crédito tributário, bem como suas formas de extinção. No segundo momento, fez-se necessário expor o instituto da dação em pagamento como forma de extinção do crédito tributário com clareza e objetividade, dando enfoque ao final na modalidade desse instituto que diz respeito a bens imóveis, além de ressaltar a lei federal sobre o assunto, e a forma pela qual os demais entes políticos devem complementar a legislação existente. E por fim, e de vital importância para o estudo, foi verificada a possibilidade da quitação do credito tributário mediante a dação em pagamento com bens móveis, exibindo os entendimentos jurisprudenciais, doutrinários e legais, mostrando legislações conflitantes entre os próprios entes políticos, além de conhecer os posicionamentos do supremo tribunal federal e seu entendimento final, que cabe ressaltar, ainda não é compreendido por vários entes políticos da federação, fazendo com que este assunto ainda seja atual e relevante para se levar a debate no mundo jurídico e acadêmico.
\end{abstract}

Palavras-chave: dação em pagamento. Sistema tributário. Legislação tributária. Crédito tributário. Direito tributário.

\begin{abstract}
This article is based on the bibliographical revision in narrative form, using the deductive method. Its objective was to understand the institute of payment in payment as a way of extinguishing the tax credit, especially with respect to the use of movable property by this institute. This issue has been discussed for a few years, but it is still the cause of legal debates, and recent laws have been published on the subject, which shows that some confusion persists, and briefly commenting on the problem. Conflicting understandings among the political entities themselves. Thus, it was preliminarily sought to present the concepts of tax credit, as well as its forms of extinction. In the second moment, it was necessary to expose the institute of payment in payment as a way of extinguishing the tax credit with clarity and objectivity, focusing on the final in the modality of this institute that concerns real estate, besides emphasizing the federal law on the and the way in which other political entities should complement existing legislation. Finally, and of vital importance to the study, it was verified the possibility of the discharge of tax credit through payment in movable property, exhibiting the jurisprudential, doctrinal and legal understandings, showing conflicting legislation among the political entities themselves, besides to know the positions of the federal supreme court and its final understanding, which is worth noting, is not yet understood by several political entities of the federation, making this subject still current and relevant to lead to debate in the legal and academic world.
\end{abstract}

Keywords: restitution in payment. Tributary system. Tributary legislation. Tributary credit. Tributary law.

\section{INTRODUÇÃO}

O presente trabalho adentra no interpretação da legislação acerca dos meios para

cenário pagamento dos tributos.
A tempos atrás o pagamento poderia ser realizado apenas por meio de pecúnia, porém

${ }^{1}$ ESPECIALISTA EM DIREITO com Pós-graduação Lato Senso em Direito Público com Ênfase em Gestão Pública com capacitação para o Ensino no Magistério Superior pela Faculdade de Direito Professor Damásio de Jesus (2015), Possui graduação em Direito pelo Centro Universitário de Goiás Uni-ANHANGUERA (2010). Atualmente é PROFESSOR UNIVERSITÁRIO na Faculdade Evangélica de Goianésia-GO (2017) e CONSULTOR JURíDICO da Câmara Municipal de Vila Propício-GO (2017), ADVOGADO militante com registro na OAB-GO sob o número 35.817. professorjeanmoura@gmail.com

${ }^{2}$ Discente da Faculdade Evangélica de Goianésia (FACEG) luiscarlosalcantara2016@gmail.com 
atualmente esse pagamento pode ser realizado através da dação. Detalhes acerca da temática são tratados no decorrer do trabalho.

Essa modernização da legislação tributária no Brasil se faz necessária para que o cidadão contribuinte mantenha suas contribuições em dia e a roda monetária do país não pare.

$\mathrm{Na}$ perspectiva metodológica, o método aqui utilizado foi o da revisão bibliográfica na forma narrativa, na modalidade dedutiva, uma vez que não são utilizadas estratégias de busca sofisticadas e exaustivas, não se esgotando todas as fontes de informações, usando a racionalização em sentido interpretativo, partindo de premissas gerais para chegar a deduções particulares.

A revisão foi feita por livros, revistas científicas, artigos, bem como, documentação diversa como suporte para a realização do trabalho.

A principal motivação para o presente estudo foram as enormes dúvidas sociais existentes quanto a possibilidade da dação em pagamento como forma de extinção do crédito tributário, fazendo necessário um estudo desta questão especialmente no que se refere a possibilidade jurídica do uso desse instituto no caso de bens móveis.

O objetivo geral desse trabalho é compreender a dação em pagamento como forma de extinção do crédito tributário, e os objetivos específicos da construção teórica em questão são: a) apresentar os conceitos do crédito tributário, bem como suas formas de extinção; b) expor o instituto da dação em pagamento e c) verificar a possibilidade da quitação do credito tributário mediante dação em pagamento de bens moveis.
A dação em pagamento no direito tributário significa uma importante alternativa para o contribuinte em relação aos seus tributos, para que, possivelmente, diminuam as inadimplências tributárias no Brasil, gerando assim um relevante impacto na economia nacional.

Destarte, esta pesquisa busca suscitar o seguinte questionamento: É possível o uso de bens móveis como forma de extinção do crédito tributário por meio do instituto da dação em pagamento?

Após a realização desta pesquisa podemos constatar que, é possível a dação em pagamento, para fins de extinção do crédito tributário, desde que, seja feita com bens imóveis, no âmbito da União.

Verificou-se ser possível que cada ente federativo legisle, por intermédio de Lei Complementar, sobre o presente tema, ou seja, utilização de bens móveis para dação em pagamento, tendo como escopo a extinção do crédito tributário, o que já tem ocorrido em alguns estados brasileiros. No entanto, o STF já decidiu ser impossível a utilização de bens móveis para fins de extinção do crédito tributário, conforme podemos ver no informativo n. ${ }^{\circ} 136 \mathrm{do}$ STF de 1998, pois para a aquisição de bens móveis derivados de tributos seria necessário além da elaboração de lei complementar - um processo de licitação para a contratação de obras, serviços e compras pela Administração Pública.

\section{DO CRÉDITO TRIBUTÁRIO:} CONCEITO E FORMAS DE EXTINÇÃO 
O Estado necessita de contribuições oriundas da população para arcar com as despesas das necessidades coletivas, para isso conta com o cidadão-contribuinte que retira de seus proventos uma quantia determinada, a qual é entregue em formato de tributo. Em troca o Estado oferece ao povo a estrutura e os serviços que são de sua competência. A arrecadação de tributos é a maior provedora das atividades financeiras do Estado, e tem previsão constitucional no art. 145 da referida carta magna.

Para Carvalho (200, p. 15):

O Direito Tributário é o ramo didaticamente autônomo do Direito, integrado pelo conjunto de proposições jurídico-normativas, que correspondam, direta ou indiretamente, à instituição, arrecadação e fiscalização de tributos.

Assim, em outras palavras poderia ser entendido como o ramo do direito que fiscaliza a levada do dinheiro pelo cidadão ate os cofres públicos, para sanar as despesas coletivas da sociedade contribuinte. Sendo assim o Direito Tributário é uma expressão do direito na forma positivada que engloba normas e princípios reguladores de uma relação jurídica desenvolvida na obrigação tributária, a qual engloba aspectos patrimoniais. Essa relação jurídica é polarizando, coexistindo a parte ativa e a parte passiva da relação.

Nogueira (1995, p.15) sobre o conceito e existência do Direito Tributário, escreve que:

O Direito Tributário continua ordenando segundo os princípios do Estado de Direito e então, em contrapeso à exigência e à coação unilateral do Fisco, é posto à disposição do obrigado um processo definitivo, por meio de vários remédios jurisdicionais disciplinados pelo próprio Estado, que outorgam ao obrigado uma tutela jurídica adequada para poder opor-se à exigência que considere injustificada.
A obrigação tributária e o crédito tributário são decorrentes de uma mesma relação jurídica, a qual é fruto de ação do sujeito passivo, que origina todo o processo.

Nas palavras de Rosa Junior (2005):

Assim, o crédito tributário consiste na formalização da relação jurídica tributária, autorizando ao Fisco, como sujeito ativo, exigir do sujeito passivo, o cumprimento da obrigação tributária principal da qual deriva. A obrigação tributária existe na lei, quando define a hipótese de incidência do tributo, efetiva-se com a ocorrência do fato gerador e formaliza-se com o lançamento, que constitui o crédito. Anteriormente ao lançamento a obrigação tributária tem natureza ilíquida porque o Fisco não tem ciência do fato gerador, o sujeito passivo não é identificado, não se conhece a lei que deve ser aplicada, qual o tributo devido, suas alíquotas e bases de cálculo, e o valor devido.

Ataliba (2002) relata que o fato gerador é a materialização da hipótese de incidência, representando o momento concreto de sua realização, que se opõe a abstração do paradigma legal que o antecede. É notório elucidar que podem ser tributados os atos nulos e os atos ilícitos, sendo que o fato tributário deve ser analisado diante da sua nudez, sem ser observados detalhes de sua construção. Nesse sentido Torres (2005, p. 372) discorre que:

Se o cidadão pratica atividades ilícitas com consistência econômica deve pagar o tributo sobre o lucro obtido, para não ser agraciado com tratamento desigual frente às pessoas que sofrem a incidência tributária sobre os ganhos provenientes do trabalho honesto ou da propriedade legítima.

É notório então que independentemente da origem do fato gerador ser licita ou ilícita, este deve ser tributado. Todos aqueles que realizarem um fato gerador poderá compor o polo passivo da relação jurídico-tributária, não sendo relevante a regularidade jurídica dos atos ou a licitude do seu objeto ou dos seus efeitos. 
Sabbag (2015) esclarece que na esfera quando é a prestação positiva ou negativa, que tributária o sujeito que integra o polo ativo da denota atos "de fazer" ou "não fazer", sem relação é o lado credor da relação intersubjetiva, nenhuma relação com patrimônio, ou seja é "os sendo os entes que podem invadir o patrimônio deveres instrumentais do contribuinte" para retirar os valores referentes ao tributo. Sendo consoantes com o art. 119 do CTN: "Sujeito ativo da obrigação é a pessoa jurídica de direito público titular da competência para exigir o seu cumprimento".

(CARVALHO, 2000, p. 287).

Diante tais informações identifica-se que a causa da obrigação tributária pode ser entendida como o vínculo jurídico que se estabelece como Sabbag (2015, p. 736 e 737) elucida sobre a chamada sujeição passiva, dizendo que esta:

É a matéria adstrita ao polo passivo da relação jurídico-tributária. Refere-se, pois, ao lado devedor da relação intersubjetiva tributária, representado pelos entes destinatários da invasão patrimonial na retirada compulsória de valores, a títulos e tributos.

A afirmação do autor é relativa ao que vem expresso no art. 121 do CTN:

Art. 121. Sujeito passivo da obrigação principal é a pessoa obrigada ao pagamento de tributo ou penalidade pecuniária.

Parágrafo único. $O$ sujeito passivo da obrigação principal diz-se:

I - contribuinte, quando tenha relação pessoal e direta com a situação que constitua o respectivo fato gerador;

II - responsável, quando, sem revestir a condição de contribuinte, sua obrigação decorra de disposição expressa em lei.

Exauridas informações sobre a composição da relação jurídico-tributária é fundamental esclarecer o objeto da obrigação tributária, o qual nas palavras de Sabbag (2015, p. 741) “equivale à prestação a que se submete o sujeito passivo diante do fato imponível deflagrador da obrigação tributária. Pode se materializar em uma prestação dotada de patrimonialidade ou de instrumentalidade." A obrigação pode ser principal: quando é uma prestação designativa do ato de pagar, afeta ao tributo e à multa; ou acessória: acontecimento motivador da obrigação estabelecida entre o sujeito ativo e o sujeito passivo. Esse vínculo jurídico existente pode ser entendido com a redação dos art. 114 e 115 do CTN:

Art. 114. Fato gerador da obrigação principal é a situação definida em lei como necessária e suficiente a sua ocorrência.

Art. 115. Fato gerador da obrigação acessória é qualquer situação que, na forma da legislação aplicável, impõe a prática ou a abstenção de ato que não configure obrigação principal.

Machado (2004, p. 150) acertadamente afirma que:

No Direito Tributário a palavra responsabilidade tem um sentido amplo e outro estrito (...) Em sentido amplo, é a submissão de determinada pessoa contribuinte ou não, ao direito do Fisco de exigir a prestação da obrigação tributária. (...) Em sentido estrito, é a submissão, em virtude de disposição legal expressa, de determinada pessoa que não é contribuinte, mas está vinculada ao fato gerador da obrigação tributária, ao direito do Fisco de exigir a prestação respectiva.

Como decorrência de toda essa relação jurídica entre sujeito passivo e ativo nasce o Crédito Tributário. A palavra crédito tem origem etimológica e significa crer ou ter confiança. Machado (2004, p.199) conceitua o instituto do crédito tributário como: “o vínculo jurídico, de natureza obrigacional, por força do qual o Estado (sujeito ativo) pode exigir do particular, o 
contribuinte ou responsável (sujeito passivo), o pagamento do tributo ou da penalidade pecuniária (o objeto da relação obrigacional)".

Em síntese o credito tributário é entendido como uma obrigação tributária exigível, decorrente de uma obrigação principal, a qual surge com a ocorrência do fato gerador. Com isso nasce o dever do sujeito passivo pagar seus créditos tributários, ou arcar com as penas pecuniárias cabíveis ao caso, nos moldes da norma expressa nos artigos 139 a 141 do CTN.

Dentro de crédito tributário tem-se o lançamento, que é o instrumento que confere a exigibilidade da obrigação tributária, dando a quantia certa e a qualidade do débito, com a formalização desses critérios, deixa de se falar em obrigação tributária e passa a figurar o crédito tributário, conforme esclarece a norma constante nos artigos 142 até 144 do CTN brasileiro.

Sabbag (2015) traz em seus escritos as finalidades ou funções do lançamento, sendo elas: verificar a ocorrência do fato gerador, determinar a matéria tributável, calcular o montante do tributo devido, identificar o sujeito passivo e propor, se caso o for, a aplicação da penalidade cabível. Assim o lançamento é ato ou procedimento privativo do Fisco.

Neste contexto, a autoridade administrativa responsável pelo procedimento, através do lançamento, torna líquida e certa a obrigação referente ao crédito tributário. $\mathrm{O}$ sujeito ativo da relação pode proceder a cobrança, pode dizer então, que o lançamento é o valor correspondente crédito tributário. Nos tributos e nas penas pecuniárias de valor fixo, o lançamento não calcula o montante devido, apenas estabelece a ocorrência do fato gerador, concretizando a matéria tributável e identificando o sujeito passivo da situação jurídica narrada.

$\mathrm{O}$ ato do lançamento constitui o crédito tributário e a partir disso surge o direito a exigibilidade do valor. Porém essa exigibilidade pode ser suspensa, como relata o art. 151 do Código Tributário Nacional.

Para Harada (2001, p. 374):

A suspensão da exigibilidade do crédito tributário é sempre de natureza temporária. A suspensão não importa na desconstituição do crédito tributário, que continua intacto desde sus constituição definitiva pelo lançamento, notificado ao sujeito passivo.

O depósito é uma modalidade suspensiva da exigibilidade do crédito tributário, comum na via judicial, sendo pouco praticado administrativamente. Machado (2004, p. 189) relata que o depósito é: "Um ato voluntário do sujeito passivo da relação tributária que pretenda suspender a exigibilidade do crédito tributário e, por isso mesmo, não depende de autorização do juiz, nem de qualquer outra autoridade". Funciona como "garantia que se dá ao suposto credor da obrigação tributária, num procedimento administrativo ou em ação judicial" (AMARO, 2008, p. 382). O parcelamento também é modalidade de suspensão do Fisco, onde o contribuinte se predispõe a carrear recursos para sanar o crédito, mas não de uma só vez.

O crédito tributário comumente é extinto através do pagamento do valor devido, porém existem inúmeros outros motivos que podem causar essa extinção, conforme o previsto no art. 156 do Código Tributário Nacional. 
O pagamento é uma previsão do art. 157 a realizada por ele próprio, por isso é chamado de 163 e 165 a 169 do CTN e é uma modalidade pagamento por antecipação.

direta de extinção do crédito tributário, prescindindo de autorização por lei e deve ser realizado em pecúnia. Já a compensação é um confronto entre créditos e débitos, para sanar o crédito tributário. A compensação não pode ser feita ao bel-prazer do contribuinte, pois carece de lei autorizativa, e de autorização do Executivo. A transação trata-se de um acordo para concessões que impõe fim ao litigio, conforme art. 840 a 850 da Lei n. 10.406/2002, neste ajuste legal, é mais uma modalidade indireta de extinção do crédito tributário, onde há reciprocidade de ônus e vantagens.

Dentre as modalidades há também a remissão que é o perdão da dívida pelo credor. A remissão depende de autorização legal para sua instituição. Esta deve sempre emanar do ente político tributante definido na Constituição da República como competente para legislar acerca do gravame descrito. Também tem-se em redação do CTN a decadência e a prescrição como causas legais que extinguem o crédito tributário, pois estará extinto o crédito se o Fisco deixar de realizar o lançamento dentro do prazo ofertado pela lei, ou deixar de executar a dívida em prazo adequado.

Sabbag (2015) escreve que após a decisão definitiva, seja na esfera administrativa ou judicial, sendo favorável ao sujeito ativo, o deposito integral efetuado no ato é convertido em renda a favor daquele, extinguindo-se o crédito tributário. O autor expõe também que nos tributos cujos sua constituição, para Sabbag (2015, p. 953) "são lançamentos sejam por homologação o sujeito, situações em que, mesmo ocorrido o fato gerador e passivo faz o pagamento com base em apuração a obrigação tributária, não haverá lançamento e, 
consequentemente, não haverá o crédito tributário".

Excluir o crédito tributário significa impedir sua constituição, ou seja, as hipóteses previstas na norma (isenção e anistia) impedem o surgimento, a constituição do crédito tributário correspondente à obrigação.

Porém o poder de isentar ou anistiar é correspondente ao poder de criar tributos ou de estabelecer penalidades. Assim Harada (2001, p. 299) enfatiza que é "sabido e ressabido que o poder de isentar é corolário ao poder de tributar. Só pode isentar quem tem o poder de tributar".

\section{DA DAÇÃO EM PAGAMENTO}

A dação em pagamento está prevista nos artigos 356 e 359 do Código Civil, sendo que esse instituto representa o ato de dar em pagamento algo em substituição à pecúnia.

A dação também pode ser conceituada como um acordo avençado entre credor e devedor, em que este último concorda em receber algo diverso do que inicialmente receberia.

Sobre esta temática Cassone (2009. p. 185) salienta que "trata-se de uma espécie de "transação", por isso que deve a dação em pagamento estar prevista em lei da pessoa política detentora da competência tributária”.

Isto significa que de acordo com o mencionado doutrinador para que haja a dação em pagamento, esta deve primeiramente ser autorizada por meio de uma lei.

\section{Alexandre (2017, p. 565) afirma:}

Em direito tributário, a prestação devida pelo sujeito passivo é pecuniária, em moeda ou cujo valor nela se possa exprimir (CTN, art. $\left.3^{\circ}\right)$, de forma que haverá dação em pagamento quando o Estado consentir em extinguir o crédito tributário mediante o recebimento de algo que não seja dinheiro.

A dação em pagamento foi noticiada normativamente com a edição da Lei Complementar n.104/2001, representando modalidade indireta de extinção do crédito, por carecer de edição de lei ordinária que estabeleça de forma clara a forma e as condições exigidas para que sejam extintos os créditos tributários pela dação em pagamento com bens imóveis.

Sabbag (2015, p.951) diz que a dação "corresponde a um procedimento administrativo que encerra a entrega voluntaria do bem imóvel pelo contribuinte-devedor."

Segundo o doutrinador Machado (2004) este instituto faz parte do Direito Privado, especificamente do Direito das Obrigações, em que o credor pode conceder a oportunidade ao devedor de cumprir com a sua obrigação fornecendo algo diverso daquilo que é efetivamente devido.

O Código Tributário Nacional traz em seu bojo normativo que o pagamento do tributo deve ocorrer mediante dinheiro ou em tudo o que se possa exprimir em moeda. Diante disso, surgem divergências no âmbito jurídico, tanto doutrinário quanto jurisprudencial, no tocante à aceitação da dação em pagamento como forma de se extinguir o crédito tributário.

É entendido que a dação em pagamento receba respaldo no art. $3^{\circ}$ do CTN, pois nele é expresso que o tributo é traduzido em prestação pecuniária ou "em cujo valor nela se possa exprimir", desse modo verifica-se a permissão para que o tributo seja pago não apenas com 
pecúnia, mas podendo ser materializado em algum bem.

A Lei 104/2001 acrescentou um dispositivo de suma importância no CTN, o art. 156.

O inciso XI do art. 156 do CTN dispõe acerca da dação em pagamento, incluindo-a no rol de formas capazes de se extinguir o crédito tributário.

No entanto, há doutrinadores pelos quais defendem que antes mesmo da entrada em vigor da mencionada lei esta possibilidade já existia. Nisto, é imperioso destacar o pensamento de Alexandrino e Paulo (2006, p. 266):

Mesmo antes da LC no 104/2001, havia autores que entendia, ser possível a quitação de tributos mediante dação em pagamento, uma vez que o artigo $3^{\circ}$ do CTN afirma ser tributo uma prestação pagável em moeda ou em valor que possa ser expresso em moeda.

Apesar desse reconhecimento legal, ainda hoje persiste dúvidas acerca da legalidade da dação em pagamento como modo de extinção do crédito tributário, existem divergências doutrinárias e jurisprudenciais a este respeito.

Por isso, justifica-se a abordagem deste tema, devido o mesmo ainda possuir polêmicas que ensejam debates e por isto esta pesquisa poderá contribuir de forma significativa no âmbito acadêmico e jurídico.

A dação em pagamento como forma de extinção do crédito tributário é constitucional, pois se encaixa ao que o art. $3^{\circ}$ da CTN denomina como "valor que possa ser expresso em moeda".

Mesmo após a Lei Complementar 104/2001 adicionar o inciso XI ao art. 156 do CTN, não se deve extirpar a definição de tributo, pois o mesmo exige que a prestação seja em moeda, o dispositivo legal já afirma: "ou cujo valor nela se possa exprimir"

$$
\text { Conforme Alexandre (2017, p. } 45 \text { e 46): }
$$

Assim, é lícito entender que o CTN permite a quitação de créditos tributários mediante a entrega de outras utilidades que possam ser expressas em moedas, deste que tais hipóteses estejam previstas no próprio texto do Código, que no seu art. 141 afirma que o crédito tributário somente se extingue nas hipóteses nele previstas.

As possibilidades de extinção do crédito previstos no rol do artigo 156 do CTN, para a maioria dos autores são taxativos, ou seja, apenas no caso dessas previsões são possíveis as extinções.

Porém, Amaro (2008, p. 330 e 331), afirma que o rol do artigo não é taxativo, mas sim exemplificativo:

O rol do art. 156 não é taxativo. Se a lei pode o mais (que vai até o perdão da dívida tributária) pode também o menos, que é regular outros modos de extinção do dever de parar tributo. A dação em pagamento, por exemplo, não figurava naquele rol até ser acrescentada pela Lei Complementar n. 104/2001; como essa lei só se refere à dação de imóveis, a dação de outros bens continua não listada, mas nem por isso se deve considerar banida. Outro exemplo, que nem sequer necessita de disciplina específica na legislação tributária, é a confusão, que extingue a obrigação se, na mesma pessoa, se confundem a qualidade de credor e a de devedor (art. 381, CC/2002). Há ainda, a novação (art. 360, CC/2002).

Conforme Machado (2010, p. 241) a dação em pagamento equivale a um contrato de compra e venda. O referido autor ainda afirma (p. 241242):

A norma do inciso XI do art. 156 do Código Tributário Nacional não autoriza a aquisição de bens imóveis sem a observância das normas do Direito Administrativo aplicáveis a aquisição desses bens pela Fazenda Pública. A questão essencial, portanto, que se estabelece para sua aplicação, diz respeito ao estabelecimento do preço do bem imóvel a ser recebido em pagamento. Seja como for, na verdade o contribuinte continua tendo o dever de pagar o tributo em dinheiro, posto que se trata de uma prestação pecuniária. A inclusão da dação em pagamento como forma de extinção do crédito tributário o confirma, pois com ela apenas se explicitou ser admitido à Fazenda 
Pública, enquanto credora, aceitar prestação diversa da que lhe é devida pelo contribuinte.

O foco, o objetivo final, do presente trabalho é a dação em pagamento por meio de bens móveis, para ser possível discorrer sobre a temática, é necessário expor a dação em pagamento por meio de bens imóveis.

Recentemente, em 16 de março de 2016 foi publicada a lei federal $n^{\circ}$ 13.259, que em seu artigo $4^{\circ}$, finalmente normatizou a dação em pagamento de bens imóveis para fins de extinção do crédito tributário, no âmbito da União.

Antes da publicação da lei federal no 13.259, a dação em pagamento por meio de bens imóveis não era possível formalmente no âmbito da União, pois faltava previsão legal, certo de que o CTN remete a regulamentação do assunto por meio de uma lei ordinária específica.

Assim, quanto ao processamento dessa forma de dação em pagamento, Neto (2016, online) afirma:

Com a previsão, os eventuais débitos tributários do sujeito passivo junto à União, e desde que já inscritos em Dívida Ativa da União (DAU), poderão ser saldados com a entrega, à Fazenda Federal, de bens imóveis pelo sujeito passivo devedor, extinguindo a relação tributária. Os bens imóveis ofertados e a serem entregues à Fazenda com o fim de se extinguir a obrigação tributária deverão, inicialmente, ser avaliados, devendo ainda estar desembaraçados e livres de quaisquer ônus que venham a onerar o imóvel. Ou seja, o bem imóvel, como não deveria deixar de ser, terá seu valor fixado em conformidade com o que dispuser o mercado de imóveis, prevalecendo o valor que melhor reflita uma operação normal de compra e venda entre interessados independentes. Tais procedimentos, especialmente quanto à forma como se dará a avaliação, serão estabelecidas em ato normativo expedido pelo Ministério da Fazenda. Por sua vez, o imóvel, uma vez avaliado e aceito como meio de se extinguir os débitos tributários, deverá abranger a totalidade do débito ou débitos que se pretende liquidar, incluindo-se nesse montante as rubricas devidas quanto a atualização, a juros, a multa e a encargos, sem desconto de qualquer natureza, e não apenas o valor do tributo em si.
Pela interpretação da referida lei é possível compreender algumas problemáticas, a seguir expostas.

Caso o devedor possua mais débito do que o valor fixado para o imóvel dado em pagamento, ele poderá complementar em dinheiro a eventual diferença. E, caso o devedor não possua condições de pagar a diferença, os valores não pagos serão normalmente enviados à cobrança.

Se o valor do bem for superior ao valor da dívida tributária o devedor não será ressarcido, a lei não contempla essa problemática, porém, é dedução lógica de que o instituto da dação em pagamento não pode ser usado como forma de operar um mercado imobiliário. Cabendo assim ao interessado aceitar ou não a dação em pagamento do seu imóvel.

As empresas optantes pelo Simples Nacional não podem ser contempladas com o instituto da dação em pagamento de bens imóveis, pelo menos não a nível federal, uma vez que tal regulamentação depende dos Estados e Municípios para serem cabíveis.

Ainda nessa temática, se o crédito tributário devido for objeto de discussão judicial, somente poderá haver a dação em pagamento de bens imóveis se houver a extinção da demanda judicial proposta.

Caberá ato expedido pelo Ministério da Fazenda regular a destinação específica dos créditos extintos por dação em pagamento.

Assim, as regras presentes na lei federal $n^{\circ}$ 13.259 valem apenas para a União, não se aplicando aos demais entes políticos. Caso os Estados, o Distrito Federal e os Municípios desejem regular a dação em pagamento em seus 
territórios, devem editar lei específica sobre o tema.

\section{O USO DE BENS MÓVEIS NA DAÇÃO EM PAGAMENTO COMO FORMA DE EXTINÇÃO DO CRÉDITO TRIBUTÁRIO}

Se for feita uma interpretação literal do art. 156, inciso XI, do CTN, verificar-se-á que a prestação substitutiva do pagamento em dinheiro somente se dará pela entrega de um bem imóvel.

A aceitação de bens móveis com a finalidade de extinção do crédito tributário vem sendo duramente criticada.

O problema maior, volta-se para a questão já exposta sobre o as hipóteses extintivas de crédito, se o rol que as prevê é taxativo ou exemplificativo, e também no que diz respeito a capacidade legislativa tributária.

Este estudo já concluiu que a maioria dos doutrinadores e juristas entendem pela taxatividade do rol do art. 156 do CTN, em virtude de o art. 141 do Código estipular que o crédito tributário regularmente constituído somente se modifica ou extingue, ou tem sua exigibilidade suspensa ou excluída, nos casos previstos no CTN, impedindo assim que novas hipóteses sejam criadas, salvo mediante a utilização de lei complementar de caráter nacional, alterando o próprio Código.

Assim, tem-se entendido que o rol é taxativo, de forma que somente é possível a extinção de crédito tributário mediante dação em pagamento de bens imóveis, jamais de móveis.
Vale ressaltar que apesar das discussões doutrinárias, em sede de provas para concurso público, tem-se o entendimento pacificado de que o rol é taxativo, de forma que somente é possível a extinção de crédito tributário mediante dação em pagamento de bens imóveis, jamais de móveis.

Um exemplo desse posicionamento foi a proposta elaborada pela Escola de Administração Fazendária (ESAF), no concurso para Auditor do Estado de Minas Gerais, realizado em 2005: "Lei ordinária pode prever a extinção do crédito tributário mediante dação em pagamento de bens móveis".

Referida afirmativa foi considerada incorreta, o que demonstra o entendimento da banca no sentido da taxatividade do rol.

Ademais, a Fundação Carlos Chagas (FCC), no concurso para Defensor Público do Estado de São Paulo, realizado em 2009, assinalou como incorreta proposição segundo a qual "a dação em pagamento em bens móveis extingue o crédito tributário".

Porém, quanto a capacidade legislativa tributária as discussões doutrinárias e dos legisladores se debatem.

A Constituição Brasileira de 1988, no seu artigo 146 e 146-A, atribuiu à lei complementar a competência, em sede de normas gerais, para dispor sobre o crédito tributário.

Nesse entendimento, verifica-se a possibilidade de aceitação da dação em pagamento em bens móveis como forma de extinção do crédito tributário, tomando-se como critério o entendimento e aceitação de cada estado. 
Cada estado-membro tem autonomia para legislar sobre lei complementar e mediante esta, admitir a dação em bens móveis como forma de extinção do crédito tributário, e em última análise, de proteção do erário público.

Existem muitos exemplos desse entendimento no ordenamento jurídico brasileiro, vejamos alguns.

A lei no 2.410, de 17 de Novembro de 2010, do Governo do Estado do Tocantins, que dispõe sobre as formas de extinção e garantias do crédito inscrito em dívida ativa, patrimonialização e alienação de bens adquiridos por adjudicação judicial ou dação em pagamento afirma (grifo nosso):

Art. $1^{\circ}$ A adjudicação de bem móvel ou imóvel em execução judicial promovida pela Administração Pública Estadual direta ou indireta, a dação em pagamento de bens móveis novos ou imóveis, seu processo de patrimonialização e alienação, bem como a compensação de inversões financeiras devidamente contabilizadas e classificadas na forma dos art. 12 e 13 da Lei Federal 4.320/64, e os créditos inscritos em dívida ativa com precatórios vencidos ou parcelas vencidas de precatórios, obedecerão ao disposto neste capítulo.

A Lei Complementar no 1 de 1993 do município de Jaraguá do Sul (SC), que dispõe sobre o Código Tributário do município, no parágrafo $5^{\circ}$ de artigo 61 , decide sobre a aceitação da dação em pagamento em bens móveis.

$\int 5^{\circ}$ A extinção de créditos de natureza tributária mediante dação em pagamento depende de atendimento às seguintes condições:

I - os bens dados em pagamento podem ser móveis ou imóveis, assim como outros de natureza econômica diversa, de reconhecida liquidez;(Redação acrescida pela Lei Complementar $n^{\circ} 46 / 2005$ ) (grifo nosso)

Por meio de Lei Complementar, também o município de Campo Grande $\backslash$ MS publicou a Lei $\mathrm{n}^{\mathrm{o}} 130$ de 09/12/2008, que altera a Lei 1.466, de 26 de dezembro de 1976 do Código Tributário de Campo Grande/MS e dispõe sobre a extinção de créditos inscritos em dívida ativa e ajuizado com a Fazenda Pública Municipal mediante dação em pagamento e dá outras providências.

No seu artigo $1^{\circ}$ acrescenta o inciso XI ao art. 44, que passou a vigorar com o acréscimo dos seguintes dispositivos:

$$
\begin{aligned}
& \text { Art. } 44 \text { - Extinguem o crédito tributário: } \\
& \text { [...] XI - dação em pagamento. } \\
& \text { Art. 2 do Capítulo I - Em qualquer fase } \\
& \text { do processo administrativo ou judicial, e } \\
& \text { havendo interesse da Administração Pública, } \\
& \text { ante a manifesta impossibilidade de o devedor, } \\
& \text { extinguir o crédito de qualquer natureza, e } \\
& \text { mediante prévia e expressa autorização, admite- } \\
& \text { se a extinção parcial ou integralmente, mediante } \\
& \text { dação em pagamento, atendido às seguintes } \\
& \text { condições: } \\
& \text { pagamento podem ser } \\
& \text { móveis ou imóveis, assim } \\
& \text { como outros de natureza } \\
& \text { econômica diversa, de } \\
& \text { reconhecida liquidez; (grifo } \\
& \text { nosso) }
\end{aligned}
$$

O Supremo Tribunal Federal já se posicionou das duas formas a respeito do tema. Primeiramente, adotou uma interpretação bem restritiva sobre o art. 141 do CTN, para ele, no julgamento da Medida Cautelar na ADI 1.917, é inconstitucional que a lei do Distrito Federal permitisse o pagamento de débitos das microempresas, das empresas de pequeno porte e das médias empresas, mediante a dação em pagamento de bens materiais destinados atender a programas de Governo do DF, sendo que um dos fundamentos da decisão foi a reserva de lei complementar para tratar sobre extinção do Crédito Tributário. 
Observe o julgado:

CRÉDITO

TRIBUTÁRIO

EXTINÇÃO. As formas de extinção do crédito tributário estão previstas no Código Tributário Nacional, recepcionado pela Carta de 1988 como lei complementar. Surge a relevância de pedido formulado em ação direta de inconstitucionalidade considerada lei local prevendo nova forma de extinção do crédito tributário na modalidade civilista da dação em pagamento. Suspensão de eficácia da Lei Ordinária do Distrito Federal de $\mathrm{n}^{\mathrm{o}}$ 1.624/97 (ADI 1917 MC, Relator(a): Min. MARCO AURÉLIO, Tribunal Pleno, julgado em 18/12/1998, DJ em 19-09-2003, p.15)

Num segundo momento, no julgamento da ADI 2.405-MC, por votação majoritária afirmouse ser possível a criação de novas hipóteses de extinção do crédito tributário na via da lei ordinária local (ADI 2.405-MC, rel. Min. Carlos Britto, julgado em 06.11.2002, DJ-e em 17.02.2006, p. 54).

Nota-se que a fundamentação se baseou em dois pilares: o pacto federativo e a interpretação segundo a qual "quem pode o mais pode o menos".

Nesta última decisão, pode-se afirmar que o STF entendeu ser constitucional uma lei ordinária do Rio Grande do Sul, pela qual admitia a extinção do crédito tributário por meio da dação em pagamento tanto de bens imóveis quanto móveis.

Retomando a sua posição inicial, após algumas discussões, o STF, em seu Informativo 136, teve o entendimento de que a dação deve ser realizada exclusivamente com bens imóveis, pois para a aquisição de bens móveis derivados de tributos seria necessário - além da elaboração de lei complementar - um processo de licitação para a contratação de obras, serviços e compras pela Administração Pública.
Assim, houve o reconhecimento de que a licitação, um instituto jurídico de Direito Administrativo, deve ser obrigatoriamente utilizada no momento de se adquirir bens móveis por parte da Administração pública, sendo assim vedada a dação em pagamento com bens móveis.

\section{CONCLUSÃO}

Com as exposições desse trabalho foi possível compreender o instituto da dação em pagamento como forma de extinção do crédito tributário.

Podemos resumir a dação em pagamento como uma forma de acordo avençado entre o credor e devedor, sendo que este último concorda em receber algo diverso do que inicialmente receberia.

Para o direito tributário, a prestação devida pelo sujeito passivo é pecuniária, em moeda ou cujo valor nela se possa exprimir, conforme o artigo $3^{\circ}$ do CTN.

A dação em pagamento como forma de pagamento do crédito tributário só nasceu no mundo jurídico no ano de 2001 com a edição da Lei Complementa no 104.

Sobre a temática, no âmbito federal existe a lei $n^{\circ} 13.259$ de 2016 que finalmente normatizou a dação em pagamento de bens imóveis para fins de extinção do crédito tributário.

As regras da referida lei não se aplicam aos demais entes políticos, devendo assim, os Estados, o Distrito Federal e os Municípios editarem suas próprias leis complementares para tratar do assunto.

Diante dessa situação, os entes políticos legislaram de forma conflitante no que diz 
respeito a possibilidade da dação em pagamento para fins de extinção do crédito tributário poder ou não ser realizada por meio de bens móveis.

Mesmo diante de uma evolução positiva nessa temática - que será corroborada por alterações legislativas - há, ainda, e continuarão a subsistir, muitas questões nebulosas a implorem clarificação e esclarecimento, não só pelo zelo para com a segurança jurídica, mas, também, para a efetiva transparência dos processos e procedimentos de natureza tributária.

Nesta trilha, o presente estudo teve a pretensão de responder a seguinte indagação: "É possível o uso de bens móveis como forma de extinção do crédito tributário por meio do instituto da dação em pagamento? "

Pode-se afirmar com clareza que a resposta é negativa.

A problemática do presente trabalha se deu por conta da discussão sobre a taxatividade do rol do art. 156 do CTN - que prevê a dação em pagamento com bens imóveis -, e também por causa do entendimento jurídico no que diz respeito a capacidade legislativa tributária.

O primeiro questionamento, como já bem posicionado, tem a resposta de que o rol é sim taxativo, sendo esse o entendimento da maioria dos doutrinadores e juristas.

Já, quanto ao segundo questionamento, ocorreu que, como os Estados, o Distrito Federal e os Municípios ficaram encarregados de editarem suas leis complementares quanto a dação em pagamento como forma de extinção do crédito tributário, no que tange a possibilidade do referido instituto ser possível por meio de bens móveis, cada ente desse teve o seu entendimento.
Vários desses entendimentos foram mostrados no presente estudo, em determinado momento um ente político dizia ser possível sim, mas outro ente dizia que não.

Não obstante, esses casos chegaram ao Supremo Tribunal Federal, que transitou nos dois entendimentos, e por fim afirmou que não é possível usar bens móveis como forma de extinção do crédito tributário por meio do instituto da dação em pagamento, editando o informativo 136, afirmando que a dação deve ser realizada exclusivamente com bens imóveis, pois para a aquisição de bens móveis derivados de tributos seria necessário - além da elaboração de lei complementar - um processo de licitação para a contratação de obras, serviços e compras pela Administração Pública.

Com tudo, como demonstrado, ainda ocorre de um ente político ou outro legislar a favor da utilização de bens móveis como forma de extinção do crédito tributário por meio da dação em pagamento, e diante dessa perspectiva o presente estudo teve o intuito de jogar luz a essa questão que ainda é debatida juridicamente.

\section{Referências}

\section{ALEXANDRE, Ricardo. Direito}

Tributário. Salvado: JusPodivm, 2017.

ALEXANDRINO, Marcelo; Paulo, Vicente. Manual de Direito Tributário. Rio de Janeiro: Impetus, 2006.

\section{AMARO, L. Direito tributário brasileiro.}

14 ed. São Paulo: Saraiva, 2008. 
ATALIBA, G. Hipótese de Incidência

Tributária. 6 ed. 3 tir. São Paulo: Malheiros, 2002.

BRASIL. Constituição (1988).

\section{Constituição da República Federativa do}

Brasil de 1988. Lex: Vade Mecum Saraiva, São

Paulo: Saraiva, 2017.

BRASIL. Lei n ${ }^{\circ} 5.172$, de 25 de outubro de 1966. Código Tributário Nacional. Lex: Vade Mecum Saraiva, São Paulo: Saraiva, 2017.

BRASIL. Lei $\mathrm{n}^{\circ} 13.259$, de 16 de março de 2016. Lex: Vade Mecum Saraiva, São Paulo: Saraiva, 2017.

BRASIL. Supremo Tribunal Federal. Ação Direta de Inconstitucionalidade $\mathrm{n}^{\circ}$ 2405-MC. Relator: Ministro Carlos Britto. Tribunal Pleno, julgado em 06 de novembro de 2002. Lex: STF v. 28 , n. 327,2006 , p. 14-56)

CARvalho, P. de B. Curso de Direito

Tributário. 13 ed. São Paulo: Saraiva, 2000.

CASSONE, V. Direito Tributário. São Paulo: Editora Atlas S.A, 2009.

HARADA, K. Direito Financeiro e

Tributário. 7 ed. São Paulo: Atlas, 2001.

MACHADO, H. de B. Curso de Direito

Tributário. São Paulo: Malheiros Editores

LTDA, 2004.

MATTAR, N. F. Pesquisa de Marketing, 2.ed. São Paulo: Atlas, 1995.

MIRANDA, Maria Bernadete. Conteúdo Jurídico do Princípio de Igualdade. $4^{\mathrm{a}}$ ed. São Paulo: Editora Malheiros, 2005

NETO, Aluisio. Dação em Pagamento em Bens Imóveis - Lei Federal no 13.259, de 2016. São Paulo: São Paulo. Disponível em: $<$ https://www.estrategiaconcursos.com.br/blog/ dacao-em-pagamento-em-bens-imoveis-leifederal-no-13-259-de-2016/>. Acesso em fevereiro de 2017.

\section{NOGUEIRA, R. B. Curso de Direito}

Tributário. 14 ed. São Paulo: Saraiva, 1995.

ROSA JUNIOR, L. E. F. da. Manual de Direito Financeiro e Direito Tributário. $18^{\mathrm{a}} \mathrm{ed}$. Rio de Janeiro: Renovar, 2005.

SABBAG, Eduardo. Manual de Direito

Tributário. $8^{a}$ ed. São Paulo: Saraiva, 2016.

TORRES, R. B. Tratado de Direito Constitucional, Financeiro e Tributário - os direitos humanos e a tributação: imunidades e isonomia. Rio de Janeiro: Renovar, 2005.

\section{ZANELLA, L. C. H. Metodologia de} Estudo e de Pesquisa em Administração. Florianópolis: Departamento de Ciências da Administração / UFSC; [Brasília] : CAPES : UAB, 2009. 